\title{
Putting Emotional Reactivity in its Place? Exploring Family-of- origin Influences on Emotional Reactivity, Conflict, and Satisfaction in Premarital Couples
}

\author{
Brandt C. Gardner \\ Oklahoma State University \\ Dean M. Busby \\ Brigham Young University - Provo, dean_busby@byu.edu \\ Andrew S. Brimhall \\ Saint Louis University \\ Follow this and additional works at: https://scholarsarchive.byu.edu/facpub \\ Part of the Other Social and Behavioral Sciences Commons
}

\section{Original Publication Citation}

Gardner, B. C., Busby, D. M., \& Brimhall, A. S. (2007). Putting emotional reactivity in its place? Exploring family-of-origin influences on emotional reactivity, conflict, and satisfaction in premarital couples. Contemporary Family Therapy, 27, 113-127.

\section{BYU ScholarsArchive Citation}

Gardner, Brandt C.; Busby, Dean M.; and Brimhall, Andrew S., "Putting Emotional Reactivity in its Place? Exploring Family-of-origin Influences on Emotional Reactivity, Conflict, and Satisfaction in Premarital Couples" (2007). Faculty Publications. 4601.

https://scholarsarchive.byu.edu/facpub/4601

This Peer-Reviewed Article is brought to you for free and open access by BYU ScholarsArchive. It has been accepted for inclusion in Faculty Publications by an authorized administrator of BYU ScholarsArchive. For more information, please contact ellen_amatangelo@byu.edu. 


\title{
Putting Emotional Reactivity in its Place? Exploring Family-of-origin Influences on Emotional Reactivity, Conflict, and Satisfaction in Premarital Couples
}

\author{
Brandt C. Gardner · Dean M. Busby · Andrew S. Brimhall
}

Published online: 28 June 2007

(C) Springer Science+Business Media, LLC 2007

\begin{abstract}
The purpose of this research was to develop a structural equation model that tested the effects of emotional reactivity on the relational health of a representative sample of 736 premarital couples. We hypothesized that partners' perceived family-of-origin experience would be predictive of partners' reports of their own and their partners' emotional reactivity. These reports were hypothesized to predict partners' reports of their own and their partners' ability to manage conflict, which were hypothesized to predict relationship satisfaction. Overall, the model fit the data quite well, with particularly interesting differences by gender. We discuss the model's fit within the larger body of literature, the potential implications and limitations of our findings, and future research considerations.
\end{abstract}

Keywords Conflict resolution · Couple relationships · Relationship quality

A common problem routinely presented to marriage and family therapists is marital conflict. One of the most widely replicated findings in the study of couple and marital relationships is the primacy of negative affect. Across methodologies (e.g., observational vs. survey, cross-sectional vs. longitudinal) and samples (e.g., premarital, newly-married, long-term married), negative emotionality or emotional reactivity has been shown to be a

Electronic Supplementary Material The online version of this article (doi:10.1007/s10591-007-9039-x) contains supplementary material, which is available to authorized users.

B. C. Gardner $(\bowtie)$

Oklahoma State University, 233 HES, Stillwater, OK 74078-6122, USA

e-mail: brandt.gardner@okstate.edu

D. M. Busby

Brigham Young University, Provo, USA

A. S. Brimhall

Saint Louis University, St. Louis, USA 
harbinger of current and/or future relationship distress and dissolution potential and often leads people to therapy (Gottman 1994; Gottman et al. 1998; Griffin 1993, 2003; Smith et al. 1990; Watson et al. 2000). Individuals who exhibit high emotional reactivity are thought to have difficulty with emotion processing and regulation, resulting in a much lower threshold for experiencing negative emotions or distressing circumstances. As such, their experience of negativity and/or distress during disagreements, conflict, or other situations that promote discomfort is likely to be amplified (Donnellan et al. 2005), a particularly problematic position due to their having fewer emotional resources with which to recover from such reactions.

Given its impact on the health of individuals, their personal relationships, and the process of therapy, significant attempts have been made to understand the origins of emotional reactivity. Several classic conceptual and clinical models suggest that emotional reactivity is a product of family-of-origin dynamics. For instance, Bowen family systems theory suggests that individuals who are "undifferentiated" (Bowen 1978) — whose emotional and intellectual dimensions are out of balance-are more likely to display emotional reactivity, which includes anxiety, rigidity, and nervousness. This inability to effectively manage emotions in general, and anxiety specifically, is thought to be handed down from one generation to the next via psychodynamic processes, and is best observed within the context of relationships (Kerr and Bowen 1988). Therapists, using this model, help clients recognize individual and familial patterns of emotional reactivity. Attachment theory asserts that family-of-origin relationships-specifically the relationship with the primary caregiver-serve as a model for future significant relationships (Cassidy and Shaver 1999). That is, through reciprocal interactions between child and caregiver, children learn what to expect from close relationships, how to maintain such relationships, and how to manage anxiety and other negative emotions. From an attachment perspective, high-intensity negative emotionality in close relationships may be the product of problematic early caregiver-child relationships. Clinically, therapists either try to repair attachment injuries from the past or focus on how those early childhood experiences are influencing the current relationship interactions.

Recent reviews of family research (e.g., Repetti et al. 2002; Troxel and Matthews 2004) have provided comprehensive literature-based models describing potential familial influences on the long-term emergence of problematic outcomes in the physical, emotional, and social health of offspring. These models suggest a "cascade effect" that begins early in the family of origin (or even in utero; see Huizink et al. 2004) and has the potential to exert a profound influence on the calibration of the emotional and physiological characteristics of the stress-response system, leading to abnormal thresholds (e.g., hypersensitivity or hyposensitivity), problematic functioning (e.g., prolonged or ineffectual arousal), and/or increased vulnerability to disease via immunosuppression. Behaviorally, such physiological functioning is often accompanied by the emotional reactivity or negative emotionality described above (El-Sheikh et al. 1989).

According to Repetti et al. (2002), this reactivity in both children and adolescents may stem from chronic exposure to a risky family environment. Risky families are characterized by "overt family conflict, manifested in recurrent episodes of anger and aggression, and deficient nurturing, especially family relationships that are cold, unsupportive, and neglectful" (p. 330), and are likely to leave children susceptible to a number of physical and emotional ailments. In their model, these authors suggest that family social, contextual, and genetic factors combine to create the maladaptive environment, out of which emerge children whose stress response system has been conditioned to be much more sensitive and whose ability to process emotions and cope with emotional difficulties has been hindered. 
These characteristics portend poor social competence during childhood and adolescence, and increase the likelihood of substance abuse and other problematic behaviors during adolescence. Although the risky family model does not forecast into adulthood-beyond suggesting mental and physical health problems-poor social competence is likely a significant factor in later romantic relationships, suggesting one possible means whereby family-of-origin dynamics may influence children's later relationship competence, satisfaction, and stability.

A similar model recently put forth by Troxel and Matthews (2004) suggests that marital dissolution and/or high levels of marital conflict trigger a cascade of negative influences on the emotional and physical well-being of children. The critical components of their model are a decline in socioeconomic status (via separation and/or divorce) and impaired parenting (e.g., decreased discipline, monitoring, and affection). These negative influences are thought to increase the likelihood of emotional dysregulation and insecurity in offspring, observed across cognitive (i.e., attributions), behavioral (i.e., social/coping skills, aggression), and affective (i.e., anger, depression, anxiety) domains. This model suggests that such emotional dysregulation - characterized by increased aggression, frequent displays of negative affect, and an overall inability to emotionally adapt to changing circumstancescontributes to physical health problems due to increased likelihood of engaging in risktaking behaviors (e.g., early and unprotected sexual encounters, substance use) and the heightened or abnormal stress-response system. Again, this model does not forecast into adulthood; nevertheless, several lines of research have established a clear relationship between family-of-origin processes and the quality of later romantic relationships.

For instance, a consistent finding among family researchers is that children who are exposed to frequent and intense marital conflict are more likely to have marital problems of their own later in life (Amato and Booth 2001). If these marital problems result in divorce, spouses and their children then face a significant array of potential difficulties, including physical and emotional health problems, financial strain, and social and educational disadvantages (Amato 2000). Furthermore, these negative effects are not confined only to the children of the divorcing couple, but subsequent generations have been found to experience lower educational attainment and increased relational conflict (Amato and Cheadle 2005). These studies and many others (for reviews see Amato 2000 and Amato and Sobolewski 2001) suggest that the model proposed by Troxel and Matthews (2004) may have farreaching implications for the long-term psychological and social/relational competence of children exposed to parental conflict and divorce and how clinicians work with these families.

Indeed, longitudinal research has documented that supportive and positive interactions observed between parents and children are predictive of more supportive and less hostile behaviors in the children's later romantic relationships, while negative and hostile parentchild interactions are predictive of increased hostility and negative affect in the communication of the children with their romantic partners years later (Conger et al. 2000). This negative emotionality and hostility has been found to uniquely predict relationship distress and even divorce in children's later romantic and marital relationships (Donnellan et al. 2005; Story et al. 2004).

Much of the marital interaction research also suggests a significant link between emotional reactivity (measured physiologically) to marital stressors and relationship outcomes. Longitudinal studies of newly-married couples in particular have demonstrated that the most robust predictors of divorce over substantial time periods are physiological measures such as the levels of stress hormones in the bloodstream following marital interaction, and the blood pressure and heart rate levels of participant couples (Gottman 
1994; Gottman and Notarius 2000; Kiecolt-Glaser et al. 2003). These findings are representative of a substantial body of literature that suggests the physiological reactivity of partners plays a significant role in the long-term satisfaction and stability of couple relationships (Robles and Kiecolt-Glaser 2003). This reactivity may be a product of exposure to a conflictual, unsupportive, and unstable family environment.

In summary, high-intensity negative emotionality is known to be a clinically relevant problem in close relationships, often leading to increased conflict and relationship dissolution. Comprehensive literature-based models suggest that this emotional reactivity may be a result of family-of-origin processes such as frequent marital conflict, divorce, low warmth, and hostility, which imbue children with a stress-response system that is dysregulated or easily activated. While these models do not move into adulthood, family and marital interaction research suggests that there is indeed a link between family-of-origin processes, children's ability to handle negative emotions, and relationship competence. The purpose of this research was to test a model of emotional reactivity that takes into consideration the impact of the family of origin, relationship functioning, and relationship satisfaction.

\section{Model}

As can be seen in Fig. 1, we hypothesize that premarital partners' reports of the impact their family-of-origin has on their romantic relationship will be predictive of their reports of their own and their partner's emotional reactivity. Furthermore, these reports are

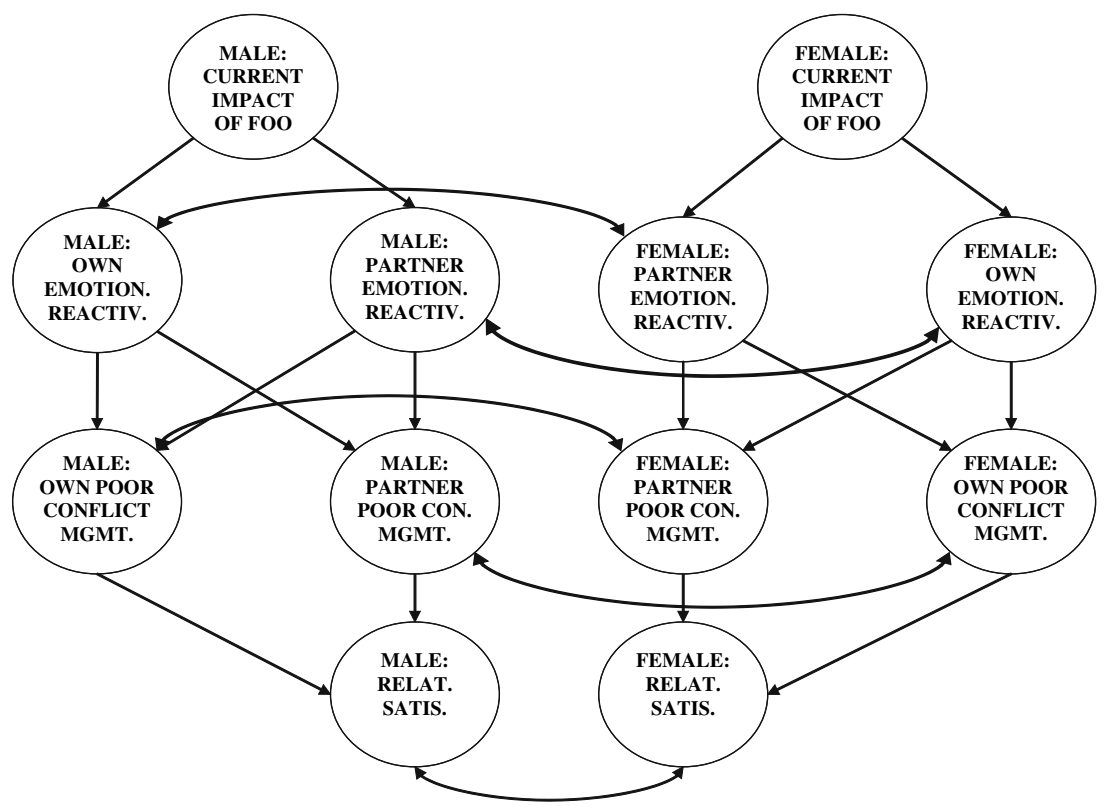

Fig. 1 Conceptual model suggesting perceptions of family-of-origin experience predict evaluations of both own and partner emotional reactivity, which then predict evaluations of both own and partner conflict management, which are ultimately predictive of relationship satisfaction. Self and partner reports of the same phenomenon are hypothesized to be correlated with one another 
hypothesized to predict evaluations of their own and their partner's ability to manage conflict, which are hypothesized to predict partners' relationship satisfaction.

A unique contribution of this research is the incorporation of both partners' assessments of their own and their partner's emotional reactivity and conflict management ability. This aspect of the study is particularly relevant to the development of programs for marriage preparation and premarital counseling, as satisfaction with a relationship may be differentially affected by perceptions of self and partner. That is, it is possible that one partner might base his or her satisfaction with the relationship on how the relationship makes him or her feel about himself or herself (e.g., "I'm really able to manage my emotions with this partner," or "I'm really able to handle our disagreements well in this relationship"), whereas the other partner might use his or her partner's behavior or emotions as the basis for satisfaction (e.g., "Clearly my partner can't control her/his negative emotions when we are together," or "My partner doesn't treat me well when we have disagreements"). Thus, obtaining both partners' perspectives on emotional reactivity and relational conflict may shed new light on how these processes differentially affect partners' relationship satisfaction.

Another important contribution of this research is the incorporation of the "current impact of family of origin" scale. This scale was designed to evaluate how respondents experienced adult relationships based on their family-of-origin experiences. That is, as a result of their family experiences, did they see relationships as likely to be rewarding, did they think relationships were safe and secure, were there issues from their family experiences still bothering them, and were these issues interfering with their adult relationships? This is a critical scale, and is one of the unique aspects of this research in that it serves as a filter through which the family-of-origin experiences pass before they influence the constructs of emotional reactivity, conflict management, and relationship satisfaction. The rationale for this scale is that it is important not only to understand what experiences occurred in the family of origin, but also to understand the perceived influence of these experiences on attitudes and experiences in adult relationships. Embedded in this scale is the idea that there is a degree of resiliency in all persons that influences how familyof-origin experiences will affect them as adults.

\section{Method}

\section{Instrument and Sample}

The data used for these analyses were taken from a database gathered using the RELATionship Evaluation (RELATE; Busby et al. 2001) instrument. The RELATE is a 271-item instrument designed to evaluate the relationship between romantically linked partners, be they dating, engaged, cohabiting, or married. The questions are designed to examine several different contexts-individual, social/cultural, family (of origin), and couple - in order to provide a comprehensive comparison and evaluation of differences in areas that may prove problematic for couples. Previous research has documented the RELATE's reliability and validity, and we refer the reader specifically to Busby et al.'s (2001) discussion of the RELATE for detailed information regarding the instrument's psychometrics. In general, analyses conducted with a variety of samples indicate that the RELATE scales typically achieve reliability coefficients between .70 and .95 . 
From a larger sample of 9,000 couples who completed the RELATE between 1997 and 2003, a subsample of 736 couples (1,472 individuals) was stratified across race and religion to resemble national norms. Only premarital couples were selected for these analyses. The demographic characteristics for this subsample included 10\% African American $(n=150)$, $3 \%$ Asian $(n=48), 3 \%$ Biracial $(n=46), 72 \%$ Caucasian $(n=1,062), 10 \%$ Latino $(n=148)$, and $1 \%$ Native American $(n=18)$. Religiously, 55\% $(n=816)$ were Protestant, $24 \%(n=360)$ were Catholic, $8 \%(n=124)$ reported no religious affiliation, $6 \%(n=92)$ reported "other religions," $3 \%(n=48)$ were Jewish, and $2 \%(n=32)$ were Latter-day Saint. In terms of education, $45 \%$ of respondents $(n=662)$ were currently enrolled in college, 30\% $(n=440)$ had received a Bachelor's degree or higher, 24\% $(n=354)$ had either some college or a high school diploma, and $1 \%(n=16)$ had less education than a high school diploma. The mean age of respondents was 25.21. All of the partners were in an exclusive relationship with one another. More than half $(65 \%, n=478)$ of the couples indicated they were in a serious dating relationship, 35\% $(n=258)$ reported being engaged, while $22 \%(n=162)$ of couples were cohabiting. Nine percent of the couples $(n=67)$ had been previously divorced.

\section{Variables and Analyses}

Structural equation modeling (SEM) was employed to evaluate the relationship between the variables of interest. SEM allows for the construction of latent variables or constructs, providing that the specific items used to specify each latent variable load significantly upon it. The CURRENT IMPACT OF FOO latent variable consisted of RELATE items designed to evaluate one's perception of how his or her family-of-origin experience was currently affecting him or her. This three-item scale consisted of Likert-scored items such as "There are matters from my family experience that I'm still having trouble dealing with/coming to terms with," and "There are matters from my family experience that negatively affect my ability to form close relationships."

The OWN and PARTNER EMOTIONAL REACTIVITY latent variables consisted of five Likert-scored personality items that asked respondents to rate themselves and their partner on descriptive items such as "fights with others/loses temper," "easily irritated or mad," and "tense." Again, individuals rated themselves for the OWN EMOTIONAL REACTIVITY variable and their partners for the PARTNER EMOTIONAL REACTIVITY variable.

The OWN and PARTNER POOR CONFLICT MANAGEMENT latent variables were constructed using nine Likert-scored interaction variables that asked respondents to rate themselves and their partner on items such as "I am able to listen to my partner in an understanding way," "There's no stopping me once I get started complaining," "When I get upset I can see glaring faults in my partner's personality," and "Whenever I have a conflict with my partner I feel physically tense and anxious, and I don't think clearly."

The RELATIONSHIP SATISFACTION latent variable consisted of eight Likert-scored items asking respondents to rate how satisfied they were with relationship processes such as, "physical intimacy," "love," "how conflicts are resolved," and "the quality of your communication."

Thus, to summarize, we created a structural model designed to evaluate the influence of individuals' perceptions of their family-of-origin experience on their reports of both their own and their partner's emotional reactivity. The emotional reactivity constructs were hypothesized to predict individuals' reports of their own and their partner's inability to 
manage relationship conflict, and these conflict management constructs were hypothesized to predict relationship satisfaction. To evaluate whether individuals' self-reports of both their own and their partners' characteristics were consistent with their partners' selfreports, the residuals of these constructs were correlated. For example, the male's report of his partner's emotional reactivity was correlated with his partner's report of her own emotional reactivity.

We utilized AMOS 4.0 (Arbuckle and Wothke 1999) structural equation modeling software to evaluate how well the structural model depicted in Fig. 1 fit the data. Due to some missing data, Maximum Likelihood Estimation was used to estimate means and intercepts. Model fit was assessed by examining the Tucker-Lewis Index (TLI; Bentler and Bonnett 1980), the comparative fit index (CFI; Bentler 1990), the normed fit index (NFI; Bentler and Bonnett 1980), and the root mean square error of approximation (RMSEA; Browne and Cudeck 1993).

\section{Results}

\section{Measurement Model}

The measurement model consists of the individual survey items (indicators) associated with each latent variable or construct. This study utilized 76 survey items to construct 12 latent variables. Evaluation of the measurement model ensures that the survey items used to construct a particular latent variable are appropriately related to one another (similar to a reliability analysis for items that make up a scale). One indicator is selected as the metric by which the other indicators for a particular latent variable are evaluated, and is set to 1.0. All other indicators are allowed to freely "load" on their respective latent constructs with a path coefficient. Loadings that receive a critical ratio (CR) greater than \pm 1.96 are significant at the .05 level. All indicators in the current study loaded significantly upon their latent variables. The lowest path coefficients in the measurement model were .159 (CR 3.94; males' reported satisfaction with time spent together $\rightarrow$ MALE: RELAT. SATIS.), .214 (CR 4.73; males' rating themselves as "fearful" $\rightarrow$ MALE: EMOTIONAL REACTIVITY), and .215 (CR 5.44; females' reported satisfaction with time spent together $\rightarrow$ FEMALE: RELAT. SATIS.). All other coefficients in the measurement model ranged from between .277 (CR 6.35) and .791 (CR 12.64). Interested readers may contact the first author for further information regarding the additional factor loadings, estimation, and identification of the measurement model.

\section{Structural Model}

A structural equation model is said to have a good fit with the data if fit indices such as the NFI and CFI are above .90, and if the RMSEA is below .05, while adequate or acceptable fit can be achieved with an RMSEA between .05 and .08 (McDonald and Ho 2002). The results of these analyses can be seen in Table 1. All paths and correlations were significant $(p<.05)$, and the fit indices suggest that the model fit the data fairly well, with values well above the recommended .90 cutoff for all measures of fit. The RMSEA of .062, while above the .05 cutoff recommended for good fit, falls well within the range for adequate or acceptable fit. While the chi-square statistic was high and significant, this statistic is 
Table 1 Standardized path coefficients, correlations, and fit indices for the structural equation analyses of the conceptual model depicted in Fig. $1(n=736$ couples, $\mathrm{df}=2,753)$

\begin{tabular}{lc}
\hline Parameter & Path coefficient \\
\hline M: Current Impact of FOO $\rightarrow$ M: Own Emot. Reactivity & .187 \\
M: Current Impact of FOO $\rightarrow$ M: Partner Emot. Reactivity & .198 \\
M: Own Emot. Reactivity $\rightarrow$ M: Own Poor Conflict Mgmt. & .613 \\
M: Own Emot. Reactivity $\rightarrow$ M: Partner Poor Conflict Mgmt. & .266 \\
M: Partner Emot. Reactivity $\rightarrow$ M: Partner Poor Conflict Mgmt. & .727 \\
M: Own Poor Conflict Mgmt. $\rightarrow$ M: Relationship Satisfaction & -.225 \\
M: Partner Poor Conflict Mgmt. $\rightarrow$ M: Relationship Satisfaction & -.534 \\
F: Current Impact of FOO $\rightarrow$ F: Own Emot. Reactivity & .251 \\
F: Current Impact of FOO $\rightarrow$ F: Partner Emot. Reactivity & .181 \\
F: Own Emot. Reactivity $\rightarrow$ F: Own Poor Conflict Mgmt. & .669 \\
F: Own Emot. Reactivity $\rightarrow$ F: Partner Poor Conflict Mgmt. & .386 \\
F: Partner Emot. Reactivity $\rightarrow$ F: Partner Poor Conflict Mgmt. & .635 \\
F: Own Poor Conflict Mgmt. $\rightarrow$ F: Relationship Satisfaction & -.234 \\
F: Partner Poor Conflict Mgmt. $\rightarrow$ F: Relationship Satisfaction & -.596 \\
Correlated Latent Variables & $r^{2}$ \\
M: Own Emot. Reactivity $\leftarrow \rightarrow$ F: Partner Emot. Reactivity & .630 \\
M: Partner Emot. Reactivity $\leftarrow \rightarrow$ F: Own Emot. Reactivity & .671 \\
M: Own Poor Conflict Mgmt. $\leftarrow \rightarrow$ F: Partner Poor Conflict Mgmt. & .565 \\
M: Partner Poor Conflict Mgmt. $\leftarrow \rightarrow$ F: Own Poor Conflict Mgmt. & .592 \\
M: Relationship Satisfaction $\leftarrow \rightarrow$ F: Relationship Satisfaction & .609 \\
\hline Pote: &
\end{tabular}

Note $: \mathrm{M}=$ Male, $\mathrm{F}=$ Female. All paths and correlations significant $(p<.05) . \chi 2=10628.33, p<.001$; $\mathrm{CFI}=0.95, \mathrm{NFI}=0.93, \mathrm{TLI}=0.95, \mathrm{RMSEA}=0.062$

sensitive to, and easily inflated by, large sample sizes, which renders it an inaccurate measure of fit for these data.

Paths from the CURRENT IMPACT OF FOO construct to the EMOTIONAL REACTIVITY constructs-both own and partner-were the weakest of the model but still significant, with the path between FEMALE: CURRENT IMPACT OF FOO and FEMALE: OWN EMOTIONAL REACTIVITY being the strongest of the four. All of the paths from the EMOTIONAL REACTIVITY constructs to the POOR CONFLICT MANAGEMENT constructs were significant, with the strongest being those from OWN EMOTIONAL REACTIVITY to OWN POOR CONFLICT MANAGEMENT and PARTNER EMOTIONAL REACTIVITY to PARTNER POOR CONFLICT MANAGEMENT (for both males and females). All paths from the POOR CONFLICT MANAGEMENT constructs to the RELATIONSHIP SATISFACTION constructs were significant, with those paths from PARTNER POOR CONFLICT MANAGEMENT constructs being substantially more predictive than the OWN POOR CONFLICT MANAGEMENT constructs for both males and females.

The correlations between the residuals of partners' reports of specific phenomena (e.g., own emotional reactivity, partner's emotional reactivity, own conflict management, partner's conflict management) were significant and very strong. For instance, the correlation between the residuals of MALE: OWN EMOTIONAL REACTIVITY and FEMALE: PARTNER EMOTIONAL REACTIVITY was .630, and the correlation between the 
residuals of FEMALE: OWN EMOTIONAL REACTIVITY and MALE: PARTNER EMOTIONAL REACTIVITY was .635. The strength of these relationships suggests some measure of accuracy for these self-report data, in that both partners are evaluating the same specific process (i.e., the male's emotional reactivity) in a very similar manner.

\section{Discussion}

Conceptual and recent literature-based models have suggested that emotional reactivity or negative emotionality may have its roots in family-of-origin processes, whereby family environments characterized as cold, unsupportive, and conflictual ultimately result in children developing a dysregulated stress-response system and a poor means of responding to negative and distressing stimuli. The marital interaction research indicates that partners who display high-intensity negative affect, who have strong physiological reactions to their partner, and who have a difficult time recovering from distressing marital interactions are much more likely to be unhappily married or divorced over time. Only a small collection of studies have established a link between these two domains, the family-of-origin processes and the competence in adult romantic relationships (see Conger et al. 2000; Donnellan et al. 2005; Story et al. 2004). The purpose of this study was to test a conceptual model that examined the influence of the family of origin on emotional reactivity, conflict management, and relationship satisfaction in a representative sample of premarital couples.

Indeed, few studies actually have studied this hypothesized cascade, that family-oforigin processes predict the development of emotional reactivity, which predicts poor conflict management, which leads to lower relationship satisfaction. Overall, our conceptual model fit the data well, suggesting support for such a process. Specifically, the results confirmed our hypotheses that individual partners' perceptions of the current impact of their family of origin is predictive of reports of both their own and their partner's emotional reactivity, both of which are predictive of their own and their partner's poor conflict management, which predict current relationship satisfaction. Validation of this model provides further support for other models linking family-of-origin processes to emotional reactivity (e.g., Repetti et al. 2002; Troxel and Matthews 2004), and emotional reactivity with poor relationship functioning and relationship satisfaction (e.g., Amato and Sobolewski 2001; Conger et al. 2000; Gottman 1993; Gottman and Levenson 1999), and contributes to a growing body of literature suggesting a framework for understanding how these various domains may be linked. Viewing this progression as a cascade is helpful for clinicians because it provides several places to intervene. We discuss some of these possibilities in more detail below, using this opportunity to highlight some clinical insights into the relationship among the constructs. Before discussing each level of the cascade, it is important to note that these constructs are circular rather than linear. Although each will be discussed separately it is assumed that intervening on one level will likely have an impact on other levels.

\section{Family-of-origin Influences}

The connections between the family-of-origin and the emotional reactivity domains, although significant, were among the weakest in the model. There are several potential explanations for this. The most obvious is that there are likely other factors that account for the development of emotional reactivity in addition to the overall perception of how one's 
family-of-origin experience is currently affecting partners and their relationships. These factors include genetics, personality traits, significant childhood experiences and other romantic relationships, specific parental and sibling relationships, and the parents' marital relationship (see Booth et al. 2000; Scaramella and Conger 2003).

Another possibility that warrants consideration is the fact that these couples were not married. There is some preliminary evidence that suggests that it is only post marriage that family of origin experiences begin to exert an observable influence on couple relationships. For example, recent research from an attachment perspective has noted change in participants' narrative coherence across the threshold of marriage (e.g., Crowell et al. 2002; Treboux et al. 2004). Coherence is a parameter scored during the Adult Attachment Interview (AAI) and the Current Relationship Interview (CRI) that indicates how clearly and vividly individuals are able to recall and discuss attachmentrelated experiences and relationships from their family of origin (AAI) and current romantic relationship (CRI). Those who are able to recall and discuss such experiences, whether positive or negative, are much more likely to be secure and well-adjusted, while those who have difficulty providing adequate or believable detail, or who become easily distracted or obsessed when discussing a particular relationship or experience, are more likely to be insecure and have relational difficulties. In the research of Crowell et al. (2002), coherence regarding current relationship dynamics (as measured by the CRI) was predictive of individuals moving from an insecure classification to a secure classification post marriage, while coherence regarding family-of-origin dynamics was not predictive of such a move. Treboux et al. (2004) suggest that such differences may be indicative of the attachment system being activated through wedding preparations and the prospect of leaving home, particularly if individuals were living with their parents prior to marriage.

These findings, coupled with insights from a dynamic systems conceptual framework (e.g., Granic and Hollenstein 2003), suggest that the threshold of marriage may operate as a "perturbation" to the relationship system, prompting a period of increased variability in individual and couple patterns with new individual and relational patterns and preferences emerging as a result of the reciprocal interactions between partners. An example of this process is provided in the report of Smith et al. (1990), who found that premarital negative affect was significantly correlated with premarital relationship satisfaction but was not correlated with postmarital satisfaction. Thus, it is possible that following marriage the couple relationship reorganizes in such a manner as to make partners' family-of-origin experiences more salient and relevant to their present circumstances. These are strictly speculative conceptual ideas; nevertheless, they do provide some potential explanations for why general family-of-origin variables may not be as predictive of emotional reactivity in the premarital couples in this study.

Despite the weakness of the path, the relationship between family-of-origin influences and emotional reactivity was significant. While this finding provides clinicians a specific area to address in therapy (the impact of the family-of-origin on relationship functioning and satisfaction), how they focus on this relationship may vary based on their conceptualization of past experiences. For example, a therapist using a Bowenian approach may focus on helping an individual differentiate from his or her family of origin before spending time on marital interactions, whereas an emotionally focused therapist (Johnson 1996) would highlight how messages from the family-of-origin are influencing the present marital interactions. Irrespective of the method, clinicians should assess the influence of the family-of-origin to better understand the role of emotional reactivity in the current relationship. 
Also, based on these findings, clinicians providing premarital counseling may want to restructure the services they provide. Generally, premarital couples receive clinical services before their wedding date. And yet, emerging literature suggests that family-of-origin influences do not entirely surface until after the couple transitions to marriage. By having post-wedding sessions, clinicians may lend support as experiences from the familyof-origin become increasingly salient to the couple's interactions (Granic and Hollenstein 2003).

\section{Gender Differences, Reactivity, and Conflict}

As clinicians descend this cascade, the next level of intervention to consider is the role gender plays in emotional reactivity and conflict resolution. There are some interesting gender differences in the paths across the middle of the model (e.g., those that move from emotional reactivity to conflict management). For instance, for males, one of the more influential constructs is their evaluation of their partners' emotional reactivity. The model suggests that if a male views his partner as being emotionally reactive, he is also very likely to not only view her as handling conflict and communication poorly, but also less likely himself to handle conflict well. A similar sequence can be identified for females, but the strength of the relationships between these constructs is less than it is for males. This finding may lend support to the importance of working with female clients to soften the manner in which they raise relationship issues for discussion (Gottman 1993, 1994; Gottman et al., 1998).

These differences become more interesting when viewed within the context of individuals' reports of the current impact of the family of origin and their reports of both their own and their partners' emotional reactivity. For males, the family-of-origin construct has slightly more of an influence on how males evaluate their partner's emotional reactivity rather than their own emotional reactivity. The opposite is true for females, suggesting that the family-of-origin construct has more influence on females' evaluation of their own reactivity rather than their partner's reactivity. Furthermore, the best predictor of poor conflict management in this model (whether it be own or partner) is the partner emotional reactivity construct for males and the own emotional reactivity construct for females.

These findings may be an artifact of females' tendency to respond to family-of-origin difficulties through internalization (e.g., self-blame/shame, depressive/anxious symptoms) whereas males resort more to externalization (e.g., aggression, acting out behaviors; Davies and Lindsay 2004). It is possible that these tendencies, learned in the family of origin, persist into adolescence and early adulthood and encourage females to take more of the "blame" for relational problems, and males to look outside themselves for causes of distress. This may partially account for the more frequent use of general relationship maintenance behaviors in women, who many suggest are socialized to be responsible for the upkeep of their relationships (Canary and Stafford 1992; Ragsdale 1996). Further work on comprehensive longitudinal models such as the risky families model (Repetti et al. 2002) and Troxel and Matthews' (2004) model may need to consider differential effects and outcomes of family-of-origin stressors on male and female offspring beyond the internalization/externalization distinction.

Understanding the role gender plays in how individuals respond to emotional reactivity and conflict may help clinicians understand a typical pursue/withdraw interaction. According to these findings, men reacted negatively to their partner's emotional reactivity. Based on their family-of-origin experiences, and their tendency to resort to externalization, 
men may view their wives as the problem and attempt to remove themselves from the situation. Women may internalize their husband's withdrawal (as they did in their familyof-origin) and blame themselves for the interaction. As a result they may pursue their husbands in an attempt to make things better. These findings provide clinicians with two possible areas for intervention. First, they may attempt to help male clients make their family-of-origin experiences and expectations more overt. This may help decrease their tendency to resort to externalization while also increasing their level of responsibility for the interaction. Second, attempts could be made to decrease the amount of internalization by female clients, which may result in less self-blame followed by a reduced need to pursue.

\section{Conflict Management and Relationship Satisfaction}

Regarding relationship satisfaction, while both males' and females' reports of their own and their partners' conflict management were predictive of relationship satisfaction, individuals' reports of their partners' conflict management was a much stronger predictor. This is consistent with the substantial empirical findings noted in the marital interaction literature that negativity during marital interactions, particularly high-intensity negativity such as hostility and contempt, are associated with lower levels of relationship satisfaction concurrently and over time (Gottman 1994; Heyman 2001).

What is interesting is the influence that the perception of one's partner's ability to handle conflict has on relationship satisfaction. Perceiving one's partner as being in control of his or her emotions and able to respond appropriately during relational conflict appears to significantly affect how satisfied one feels about the relationship. This raises an interesting question regarding attributions in relationships. Relationship attributions- the perceived meaning that one partner assigns to the other's behavior-are known to exert a significant influence on the course that marital discussions and conflicts take. Specifically, individuals who interpret their partners' behaviors as more negative or motivated by negative agendas are more likely to be more negative themselves and less likely to demonstrate positive communication skills such as self-disclosure and agreement (Johnson et al. 2001). Clinicians may wish to highlight the tendency of each partner to minimize their role in the conflict while simultaneously maximizing their partners' responsibility. By making these negative attributions overt, the couple may learn to manage conflict effectively and increase their chances of being satisfied. While a great deal of research has investigated attributions and their influence on relationship processes and outcomes, very little research has explored the potential link between family-of-origin experiences and attributions in close relationships (for an exception see Matthews and Conger 2004). This may be a fruitful line of research, one that raises interesting possibilities for cognitive approaches to couples' educational and therapeutic endeavors.

\section{Limitations, Future Research, and Conclusions}

Our findings need to be considered within the context of several limitations. First of all, this study utilized cross-sectional self-reports from a representative sample of premarital couples. Although recent research has demonstrated that such data is closely related to findings obtained via observation of couple interaction (see Stanley et al. 2002), it is generally accepted that observational research may be a more accurate means of obtaining 
information on couple communication processes. Furthermore, as this data was collected at only one point in time, our findings cannot speak to the potential long-term impact of emotional reactivity and poor conflict management on relationship satisfaction.

As the sample for these analyses were premarital couples, we do not recommend generalization of these findings to married couples, even those who are newly-married. It is possible that the threshold of marriage elicits a reorganization of the relationship system such that novel patterns, preferences, and processes emerge in the post-marital relationship that were previously absent or undetected (e.g., Granic and Hollenstein 2003). Moreover, the relationships from partners' family-of-origin constructs to the emotional reactivity constructs were among the weakest in the model, suggesting there may be other variables (e.g., contextual factors, genetics, specific parental relationships) that better account for the development of emotional reactivity.

Continued research in this area is critical. It is becoming more apparent that couple relationships cannot be studied as isolated phenomena as they are greatly influenced by a variety of historical, contextual and relational factors (Busby et al. 2005). Developmental approaches to the study of family influences on close relationships (e.g., Conger et al. 2000) will likely continue to yield some of the most useful information for both researchers and practitioners. However, there is growing sentiment that the sheer number of potential pressures and variables that can be brought to bear on relationship systems make attempts at long-term prediction speculative at best (e.g., Lewis 2000).

Nevertheless, the syntheses of growing bodies of literature documenting family influences on child health and development into coherent, applicable models such as those proposed by Repetti et al. (2002) and Troxel and Matthews (2004) is sorely needed, with the next steps being: (1) rigorous empirical evaluation of specific model components, and (2) extension of these models into later stages of life. Further attempts to link psychological and relational research with biological and physiological methodologies and processes are likely to continue to shed additional light on how specific behavioral characteristics emerge within family and couple relationships.

Despite its weaknesses, our conceptual model fit the data well, and, in addition to providing support for other developmental models of family-of-origin influences on individual development (e.g., the risky families model) and relationship functioning (e.g., attachment theory), suggests interesting relationships among self and partner perspectives with regard to reactivity, conflict, and relationship satisfaction. Furthermore, understanding this cascade of reactivity and conflict provides clinicians several opportunities to develop interventions that may ultimately increase marital satisfaction. Finally, our findings reemphasize the need for researchers to obtain both self and partner reports of individual and couple variables during research, evaluation, education, and intervention (Whisman et al. 2004).

Acknowledgments This research was partially supported by funding from the College of Human Sciences at Texas Tech University and by the Family Studies Center at Brigham Young University. An earlier version of this research was presented at the 2003 Annual Conference of the National Council on Family Relations in Vancouver, British Columbia, Canada.

\section{References}

Amato, P. R. (2000). Consequences of divorce for adults and children. Journal of Marriage and the Family, $62,1269-1287$. 
Amato, P. R., \& Booth, A. (2001). The legacy of parents' marital discord: Consequences for children's marital quality. Journal of Personality and Social Psychology, 81, 627-638.

Amato, P. R., \& Cheadle, J. (2005). The long reach of divorce: Divorce and child well-being across three generations. Journal of Marriage and Family, 67, 191-206.

Amato, P. R., \& Sobolewski, J. M. (2001). The effects of divorce and marital discord on adult children's psychological well-being. American Sociological Review, 66, 900-921.

Arbuckle, J. L., \& Wothke, W. (1999). Amos 4.0 user's guide. Chicago: SPSS.

Bentler, P. M. (1990). Comparative fit indexes in structural models. Psychological Bulletin, 107, $238-246$.

Bentler, P. M., \& Bonnett, D. G. (1980). Significance tests and goodness of fit in the analyses of covariance structures. Psychological Bulletin, 88, 588-606.

Booth, A., Carver, K., \& Granger, D. A. (2000). Biosocial perspectives on the family. Journal of Marriage and the Family, 62, 1018-1034.

Bowen, M. (1978). Family therapy in clinical practice. New York: Jason Aronson.

Browne, M. W., \& Cudeck, R. (1993). Alternative ways of assessing model fit. In K. A. Bollen \& J. S. Long (Eds.), Testing structural equation models (pp. 136-162). Newbury Park, CA: Sage.

Busby, D. M., Gardner, B. C., \& Taniguchi, N. (2005). The family of origin parachute model: Landing safely in adult romantic relationships. Family Relations, 54, 254-264.

Busby, D. M., Holman, T. B., \& Taniguchi, N. (2001). RELATE: Relationship evaluation of the individual, family, cultural, and couple contexts. Family Relations, 50, 308-316.

Canary, D. J., \& Stafford, L. (1992). Relational maintenance strategies and equity in marriage. Communication Monographs, 59, 243-267.

Cassidy, J., \& Shaver, P. R. (1999). Handbook of attachment: Theory, research and clinical applications. New York: Guilford Press.

Conger, R. D., Cui, M., Bryant, C. M., \& Elder, G. H. (2000). Competence in early adult romantic relationships: A developmental perspective on family influences. Journal of Personality and Social Psychology, 79, 224-237.

Crowell, J. A., Treboux, D., \& Waters, E. (2002). Stability of attachment representations: The transition to marriage. Developmental Psychology, 38, 467-479.

Davies, P. T., \& Lindsay, L. L. (2004). Interparental conflict and adolescent adjustment: Why does gender moderate early adolescent vulnerability? Journal of Family Psychology, 18, 160-170.

Donnellan, M. B., Larsen-Rife, D., \& Conger, R. D. (2005). Personality, family history, and competence in early adult romantic relationships. Journal of Personality and Social Psychology, 88, 562-576.

El-Sheikh, M., Cummings, E. M., \& Goetsch, V. L. (1989). Coping with adults' angry behavior: Behavioral, physiological, and verbal responses in preschoolers. Developmental Psychology, 25, 490-498.

Gottman, J. M. (1993). A theory of marital dissolution and stability. Journal of Family Psychology, 7, 5775.

Gottman, J. M. (1994). What predicts divorce? The relationship between marital processes and marital outcomes. Mahwah, NJ: Erlbaum.

Gottman, J. M., Coan, J., Carrere, S., \& Swanson, C. (1998). Predicting marital happiness and stability from newlywed interactions. Journal of Marriage and the Family, 60, 5-22.

Gottman, J. M., \& Levenson, R. W. (1999). What predicts change in marital interaction over time? A study of alternative models. Family Process, 38, 143-158.

Gottman, J. M., \& Notarius, C. I. (2000). Decade review: Observing marital interaction. Journal of Marriage \& the Family, 62, 927-947.

Granic, I., \& Hollenstein, T. (2003). Dynamic systems methods for models of developmental psychopathology. Development and Psychopathology, 15, 641-669.

Griffin, W. A. (1993). Transitions from negative affect during marital interaction: Husband and wife differences. Journal of Family Psychology, 6, 230-244.

Griffin, W. A. (2003). Affect pattern recognition: Using discrete hidden Markov models to discriminate distressed from nondistressed couples. Marriage \& Family Review, 34, 139-163.

Heyman, R. E. (2001). Observation of couple conflicts: Clinical assessment applications, stubborn truths, and shaky foundations. Psychological Assessment, 13, 5-35.

Huizink, A. C., Mulder, E. J. H., \& Buitelaar, J. K. (2004). Prenatal stress and risk for psychopathology: Specific effects or induction of general susceptibility? Psychological Bulletin, 130, 115-142.

Johnson, S. M. (1996). The practice of emotionally focused marital therapy: Creating connection. Florence, KY: Brunner/Mazel.

Johnson, M. D., Karney, B. R., Rogge, R., \& Bradbury, T. N. (2001). The role of marital behavior in the longitudinal association between attributions and marital quality. In V. Manusov, \& J. H. Harvey (Eds.), Attributions, communication behavior, and close relationships (pp. 173-192). New York: Cambridge University Press. 
Kerr, M. E., \& Bowen, M. (1988). Family evaluation. New York: W. W. Norton.

Kiecolt-Glaser, J. K., Bane, C., Glaser, R., \& Malarkey, W. B. (2003). Love, marriage, and divorce: Newlywed's stress hormones foreshadow relationship changes. Journal of Consulting and Clinical Psychology, 71, 176-188.

Lewis, M. D. (2000). The promise of dynamic systems approaches for an integrated account of human development. Child Development, 71, 36-43.

Matthews, L. S., \& Conger, R. D. (2004). "He did it on purpose!" Family correlates of negative attributions about an adolescent sibling. Journal of Research on Adolescence, 14, 257-284.

McDonald, R. P., \& Ho, M. R. (2002). Principles and practice in reporting structural equation analyses. Psychological Methods, 7, 64-82.

Ragsdale, J. D. (1996). Gender, satisfaction level, and the use of relational maintenance strategies in marriage. Communication Monographs, 63, 354-369.

Repetti, R. L., Taylor, S. E., \& Seeman, T. E. (2002). Risky families: Family social environments and the mental and physical health of offspring. Psychological Bulletin, 128, 330-336.

Robles, T. F., \& Kiecolt-Glaser, J. K. (2003). The physiology of marriage: Pathways to health. Physiology \& Behavior, 79, 409-416.

Scaramella, L. V., \& Conger, R. D. (2003). Intergenerational continuity of hostile parenting and its consequences: The moderating influence of children's negative emotional reactivity. Social Development, $12,420-439$.

Smith, D. A., Vivian, D., \& O'Leary, K. D. (1990). Longitudinal prediction of marital discord from premarital expressions of affect. Journal of Consulting and Clinical Psychology, 58, 790-798.

Stanley, S. M., Markman, H. J., \& Whitton, S. W. (2002). Communication, conflict, and commitment: Insights on the foundations of success from a national survey. Family Process, 41, 659-675.

Story, L. B., Karney, B. R., Lawrence, E., \& Bradbury, T. N. (2004). Interpersonal mediators in the intergenerational transmission of marital dysfunction. Journal of Family Psychology, 18, 519-529.

Treboux, D., Crowell, J. A., \& Waters, E. (2004). When "new" meets "old": Configurations of adult attachment representations and their implications for marital functioning. Developmental Psychology, $40,295-314$.

Troxel, W. M., \& Matthews, K. A. (2004). What are the costs of marital conflict and dissolution to children's physical health? Clinical Child and Family Psychology Review, 7, 29-57.

Watson, D., Hubbard, B., \& Wiese, D. (2000). General traits of personality and affectivity as predictors of satisfaction in intimate relationships: Evidence from self- and partner-ratings. Journal of Personality, $68,413-449$.

Whisman, M. A., Uebelacker, L. A., \& Weinstock, L. M. (2004). Psychopathology and marital satisfaction: The importance of evaluating both partners. Journal of Clinical and Consulting Psychology, 72, 830838 . 